\title{
Estrutura actancial em Mawé (Tupí)
}

\author{
Dulce do Carmo Franceschini ${ }^{1}$
}

\section{Resumo}

Apresento neste artigo uma análise da estrutura actancial da língua Mawé com base na proposta de Gilbert Lazard. Mostro que a língua Mawé pode ser considerada uma língua dual, uma vez que apresenta duas construções uniactanciais de mesma importância, sendo que o actante único (Z) é tratado em uma dessas construções como o participante agentivo (X) da construção de ação biactancial; e na outra construção uniactancial, o actante (Z) é tratado como o participante passivo $(\mathrm{Y})$ da construção biactancial.

Palavras-chave: Línguas indígenas, língua Mawé, estrutura actancial, actantes verbais.

\section{Abstract}

In this paper I present an analysis of the actantial structure of the Mawé language based on Gilbert Lazard's proposal. I will show that the Mawé language should be considered a dual language in the sense that it presents two uniactantial constructions of equal importance, in which the only actant $(Z)$ is treated in one of these constructions as representing the agentive participant $(\mathrm{X})$ of the biactantial construction, whereas in the other uniactantial construction, the actant $(\mathrm{Z})$ is treated as the passive participant $(\mathrm{Y})$ of the biactantial construction.

Keywords: Indian languages, Mawé language, Actantial structure, Verbal actants.

\section{Introdução}

A língua Mawé ${ }^{2}$ é classificada como membro único da família de mesmo nome, pertencente ao Tronco Tupí (cf. Rodrigues 1984-85). É falada pelo povo Mawé, que compreende uma população de 9.156 pessoas. Esse povo vive em sua maioria na Terra Indígena Andirá-Marau, baixo Amazonas, a qual se encontra dividida administrativamente em três sub-regiões pertencentes a diferentes municípios do Estado do Amazonas: Parintins, Barreirinha e Maués.

Neste artigo, apresento uma análise da estrutura actancial da língua Mawé com base na proposta de análise da estrutura actancial das línguas

\footnotetext{
${ }^{1} \mathrm{UFU} / \mathrm{UnB}$-LALI.

2 Língua também conhecida pelo nome Sateré-Mawé, sendo que o termo Sateré designa um dos principais clãs dessa nação indígena.
} 
de Gilbert Lazard (1994). Antes, porém, de passar à análise da estrutura actancial do Mawé, farei uma breve apresentação do seu sistema verbal.

Nesta língua, os verbos podem ser agrupados em duas grandes classes: os verbos de estado, que são uniactanciais e apresentam uma construção inativa; e os verbos de processo, que podem ser empregados tanto com uma construção ativa, quanto com uma construção inativa, parte deles sendo uniactancial e outra parte biactancial.

As construções ativa e inativa se distinguem por apresentarem diferentes índices pessoais. Enquanto que a construção ativa apresenta os índices pessoais da série A (ativa), a construção inativa apresenta os índices pessoais da série I (inativa), uns e outros prefixados à base verbal:

\section{Prefixos pessoais do Mawé}

\begin{tabular}{|l|l|l|}
\hline Pessoa & Série A (ativa) & Série I (inativa) \\
\hline $1^{\text {a }}$ sg. & a- & u- \\
\hline $2^{\text {a }}$ sg. & e- & e- \\
\hline $3^{\text {a }}$ não-cor. sg. & $\emptyset-$ & i- \\
$3^{\text {a }}$ cor. sg. & to- & to- \\
\hline $1^{\text {a } \text { excl. }}$ & uru- & uru- \\
\hline $1^{\text {a } \text { incl. }}$ & wa- & a- \\
\hline $2^{\text {a }}$ pl. & ewe- $\sim$ ewei- & e- \\
\hline $\begin{array}{l}3^{\text {a }} \text { não-cor. pl. } \\
3^{\text {a } c o r . ~ p l . ~}\end{array}$ & ta'atu- $\sim$ te'ero- & $\begin{array}{l}\text { i'atu- } \\
\text { ta'atu- }\end{array}$ \\
\hline
\end{tabular}

As construções ativa e inativa se distinguem também pelos índices de relação que apresentam; esses índices indicam cumulativamente a orientação (diátese) e o aspecto lexical do verbo (télico e atélico) ${ }^{3}$. Enquanto que os índices de relação da construção inativa indicam uma orientação atributiva quando utilizados com verbos de estado, ou uma orientação inversa $a^{4}$ quando utilizados com verbos de processo, os da construção ativa podem indicar uma orientação ativa, recíproca ou média, e servem para classificar os verbos de processo em dois grandes grupos: o dos verbos ativos, os quais são compatíveis com os morfemas das vozes ativa e recíproca e o dos verbos médios, compatíveis com o morfema da voz média.

\footnotetext{
3 Sobre o aspecto lexical dos verbos em Mawé, ver Franceschini (2010).

4 Sobre a voz inversa em Mawé, ver Franceschini (2002).
} 
Segundo a compatibilidade dos lexemas verbais com os diferentes índices pessoais e de relação, podemos agrupá-los em diferentes classes:

(a) verbos de estado: compatíveis com os índices pessoais inativos e da voz atributiva, conforme mostram os exemplos abaixo:

(1) u - he - sy'at

p. $1 \mathrm{I}^{5} .+$ Atr. $\mathrm{I}^{6}+{ }^{6}$ estar com fome'

"Eu estou com fome."

(2) $\quad$ e $\quad-$ i $-\tan$

p.2pl.I.+Atr.II ${ }^{7}+$ 'estar/ser grande'

"Vocês estão grandes."

(b) verbos de processo: compatíveis com os índices pessoais ativos e inativos:

(b.1) verbos ativos: compatíveis com os índices da voz ativa ou recíproca, quando em construções ativas, conforme mostram os exemplos abaixo:

(3) a - ti - tek-tek pira

p. $1 \mathrm{~A}^{8} .+$ At. $\mathrm{I}^{9}+$ 'cortar' 'peixe'

"Eu cortei o peixe."

(4) hirokat wo'o-moweuka'i - hat - ria $\emptyset$ - to'o-suk kyse wo. 'criança' det. ${ }^{10}+$ 'brigar' + NOM. ${ }^{11}+$ pl. p.3A. + Rec. ${ }^{12}+$ 'furar' 'faca' posp. ${ }^{13}$ "As crianças briguentas (que brigaram uma com a outra) se furaram com faca."

(b.2) verbos médios: compatíveis com o índice da voz média, quando em construções ativas, conforme mostram os exemplos abaixo:

\footnotetext{
${ }_{6}^{5}$ Prefixo pessoal da série inativa.

${ }^{6}$ Atributivo da série I.

${ }^{7}$ Atributivo da série II.

${ }^{8}$ Prefixo pessoal da série ativa.

${ }^{9}$ Orientação verbal ativa.

${ }^{10}$ Determinante.

${ }^{11}$ Nominalizador.

${ }^{12}$ Orientação verbal recíproca.

${ }^{13}$ Posposição.
} 
(5)

$$
\begin{aligned}
& \text { korowi } \quad \emptyset \quad-\text { to } \quad \text { - ket } \\
& \text { 'Korowi' } \quad \text { p.3A.+ Med. } \text { I }^{14}+\text { 'dormir' } \\
& \text { "Korowi dorme / está dormindo.” }
\end{aligned}
$$

(6) korowi $\min \quad \emptyset-\emptyset \quad-’ e$

Korowi 'mergulhar' p.3A.+ Med.II + 'dizer/fazer'

"Korowi mergulhou."

\section{Estrutura actancial do Mawé}

A língua Mawé apresenta uma estrutura actancial dual (ou ativa ${ }^{15}$ ). Segundo Lazard (1994), em línguas desse tipo, o actante único tem um status gramatical diferente, conforme o participante que ele representa seja ou não um agente. $O$ papel semântico desse participante difere segundo a natureza do processo designado pelo verbo - ativo com determinados verbos e inativo com outros. Nessas línguas, o actante único $(Z)$ é tratado ou como o actante agentivo $(\mathrm{X})$ ou como o paciente $(\mathrm{Y})$ das frases de ação bi-actanciais.

As línguas que apresentam uma estrutura dual dividem em dois o conjunto de construções uniactanciais:

(1) $Z=X$

(2) $Z=Y$

Segundo Lazard (1994), nessas línguas não há uma estrutura que domine, ambas estando em pé de igualdade.

Tanto para Lazard (1994) quanto para Creissels (2006), a noção de estrutura dual não se situa no mesmo plano que as noções de estrutura acusativa e ergativa. Enquanto que as estruturas acusativa e ergativa caracterizam o alinhamento de construções uniactanciais consideradas individualmente, ou seja, alinhadas ou com X (acusativa), ou com Y (ergativa), sendo que uma ou outra predomina na língua, a dual (ou ativa) não remete a um tipo de alinhamento, mas a um tipo possível de distribuição do alinhamento acusativo e do alinhamento ergativo no léxico verbal.

Para compreendermos a distribuição do alinhamento acusativo e do alinhamento ergativo no léxico verbal do Mawé, faz-se necessário compreender o funcionamento dos verbos ativos nesta língua.

\footnotetext{
${ }^{14}$ Orientação verbal média.

${ }^{15}$ Termo empregado por G. A. Klimov em seu artigo "On the character of languages of active typology", Linguistics 131:11-25, 1974.
} 
Esses verbos requerem (ou admitem) dois actantes, sendo que um deles fará referência ao participante agente $(\mathrm{X})$ e o outro ao paciente $(\mathrm{Y})$ do processo denotado pelo verbo. Na construção ativa, o primeiro actante será indiciado no verbo e fará referência ao participante agente (X). Já na construção inativa, o participante $(\mathrm{Y})$ é que será indiciado no verbo e o participante agente poderá ou não ocorrer no enunciado sob a forma de um constituinte nominal.

O emprego dessas duas construções com verbos ativos depende, no entanto, da hierarquia de pessoa ${ }^{16}$ que opera nesta língua, segundo a qual a primeira pessoa se encontra em um grau mais elevado da hierarquia, predominando em relação à segunda pessoa e essas, primeira e segunda pessoa, predominando sobre a terceira pessoa $(1>2>3)$.

A construção ativa é empregada, portanto, se a primeira ou segunda pessoa fazem referência ao agente e a terceira ao paciente do processo denotado pelo verbo, conforme mostram os exemplos abaixo:

$$
\begin{array}{ll}
a \quad-\text { ti }- \text { a-tek } & \text { pira } \\
\text { p.1A.+ At.I + 'forma arredondada+cortar' 'peixe' } \\
\text { 'Eu corto (o) peixe.' }
\end{array}
$$

$$
\begin{aligned}
& e \quad-\text { ti - 'auka wewato } \\
& \text { p.1A.+ At.I + 'matar' 'anta' (ou 'boi') } \\
& \text { 'Você matou (a) anta/boi.' }
\end{aligned}
$$

Já a construção inativa é empregada quando a primeira ou segunda pessoa faz referência ao paciente e a terceira pessoa faz referência ao agente, conforme mostram os exemplos abaixo:

$$
\begin{aligned}
& u-\mathrm{i}-\text { tek (mi'i) } \\
& \text { p.1I.+Inv. }{ }^{17+} \text { 'cortar' 'ele' } \\
& \text { 'Eu fui cortado (por ele).' }
\end{aligned}
$$

$$
\begin{aligned}
& e \quad-\mathrm{i}-\text { tek } \quad \text { (mi'i) } \\
& \text { p.2pl.I.+Inv.+'cortar' 'ele' } \\
& \text { 'Vocês foram cortados (por ele).' }
\end{aligned}
$$

\footnotetext{
16 Essa é uma característica de muitas línguas Tupí.

17 Orientação verbal inversa.
} 
(11)

$$
\begin{aligned}
& \text { a - i - hymu:t (mi'i) } \\
& \text { p.1Incl.I.+Inv.+'acordar' 'ele' } \\
& \text { 'Nós fomos acordados (por ele).' }
\end{aligned}
$$

A construção inativa também é empregada quando a primeira pessoa faz referência ao paciente e a segunda ao agente do processo denotado pelo verbo, conforme mostram os exemplos abaixo:

$$
\begin{aligned}
& u \quad-\mathrm{i} \quad-\text { hymu:t } \quad \text { (en/eipe) } \\
& \text { p.1I.+Inv.+'acordar' (por você/vocês) } \\
& \text { 'Eu fui acordado (por você/vocês).' }
\end{aligned}
$$

$$
\begin{aligned}
& \text { uru } \quad-\emptyset \quad-\text { hymu:t (en/eipe) } \\
& \text { p.1Excl.I.+Inv.+'cortar' (você/vocês) } \\
& \text { 'Nós fomos acordados (por você/vocês).' }
\end{aligned}
$$

No entanto, quando o agente e o paciente são referenciados pela terceira pessoa, podem ser empregadas tanto a construção ativa quanto a inativa. O emprego dessas construções depende de critérios pragmático-discursivos, sendo que o emprego da construção ativa topicaliza o agente e o da inativa o paciente, conforme mostram os exemplos (14) e (15), respectivamente:

$$
\begin{aligned}
& \text { hirokat - ria } \emptyset \quad-t u-\text {-’u pyru kupu } \\
& \text { 'criança'+pl. p.3 A. +At.I+'comer' 'muito' 'cupuaçu' } \\
& \text { 'As crianças comeram muito cupuaçu.' }
\end{aligned}
$$

$$
\begin{aligned}
& \text { hirokat - ria neke } i \quad-i \quad-' u \text { pyru } \\
& \text { 'criança'+pl. anaf. }{ }^{18} \quad \text { p.3 I. + Inv.+'comer' 'muito' } \\
& \text { 'Pelas crianças, aquele é muito comido.' }
\end{aligned}
$$

Nessas construções, em que o agente e o paciente são referenciados pela terceira pessoa, a posição do constituinte nominal que é indiciado no verbo é pertinente:

${ }^{18}$ Anafórico. 
(a) Nas construções ativas, o constituinte nominal que precede imediatamente o verbo faz referência ao agente e se encontra indiciado no verbo, conforme mostram os exemplos (14) acima, e (16) abaixo:

$$
\begin{aligned}
& \operatorname{kurum}(Y) \quad \text { korowi }(X) \quad \emptyset \quad \text { - ti- pytyk } \\
& \text { 'menino' 'korowi' } \quad \text { p.3 A.+At.I+'pegar' } \\
& \text { 'O menino, Korowi o pegou.' }
\end{aligned}
$$

(b) Nas construções inativas, o constituinte nominal que precede imediatamente o verbo faz referência ao paciente e se encontra indiciado no verbo, conforme mostram os exemplos (15) acima, e (17) abaixo:

$$
\begin{aligned}
& \text { surara }(X) \quad \text { korowi }(Y) \text { i } \quad \text { - i } \quad \text { - pytyk } \\
& \text { 'soldado' 'korowi' p.3 I.+Inv.+' 'pegar' } \\
& \text { 'Pelo soldado, Korowi foi pego.' }
\end{aligned}
$$

Nessas construções, a posição do constituinte nominal não indiciado no verbo depende de estratégias pragmático-discursivas, portanto da intenção do locutor. No entanto, quando a primeira pessoa faz referência ao agente e a segunda do singular ao paciente do processo denotado pelo verbo, os verbos biactanciais ativos são prefixados pelo morfema \{moro- $\sim$ woro- $\sim$ oro- $\}$; se a primeira pessoa é o agente e a segunda do plural é o paciente, acrescenta-se o morfema $\{$-ho'o- $\}$ ao morfema \{moro- $\sim$ woro- $\sim$ oro- $\}$; temos, então, as seguintes formas prefixadas ao verbo:

(a) $1^{\text {a }}$ Agente $>2^{\text {a }}$ sg. Paciente $\rightarrow$ \{moro- $\sim$ woro- $\sim$ oro- $\}$ :

(18) moro - hymu:t 'eu te acordo/acordei.'

(b) $1^{\text {a }}$ Agente $>2^{\text {a }}$ pl. Paciente $\rightarrow$ \{moro-ho'o $\sim$ woro-ho'o $\sim$ oro-ho'o $\}$ :

(19) moro- ho'o - hymu:t 'eu acordo/acordei vocês.'

Pode-se considerar essas construções como neutras do ponto de vista pragmático-discursivo, uma vez que nelas nem o agente $(\mathrm{X})$, nem o paciente (Y) é topicalizado. 


\section{Construções uniactanciais}

Em Mawé, os verbos de estado são verbos uniactanciais nos quais o actante único $(\mathrm{Z})$ apresenta a mesma forma que o paciente $(\mathrm{Y})$ das frases de ação biactanciais, o que se configura como um alinhamento ergativo $(\mathrm{Z}=\mathrm{Y})$, conforme mostram os exemplos abaixo:

$$
\begin{aligned}
& u-\mathrm{i}-\text { tek (mi'i) } \\
& \text { p.1I.+Inv.+'cortar' 'ele' } \\
& \text { 'Eu fui cortado (por ele).' }
\end{aligned}
$$

$$
\begin{aligned}
& u \quad-\mathrm{i} \quad-\text { we'ese } \\
& \text { p.1I.+ Atr.I+'estar feliz' } \\
& \text { 'Eu estou feliz.' }
\end{aligned}
$$

Em (20), tem-se um verbo ativo biactancial no qual o participante indiciado pelo prefixo pessoal $\{\mathrm{u}-\}$ "primeira pessoa" faz referência ao actante paciente (Y) do processo denotado pelo verbo. Já em (21), que apresenta a mesma construção que (20), tem-se um verbo uniactancial e o participante indiciado nesse verbo pelo morfema $\{\mathrm{u}-\}$ faz referência ao actante único (Z). Pode-se dizer, portanto, que o alinhamento dos verbos de estado é um alinhamento ergativo, uma vez que o actante único $(Z)$ dessas construções apresenta a mesma forma que o paciente $(\mathrm{Y})$ das construções biactanciais.

Do ponto de vista semântico-referencial, nos verbos de estado o actante (Z) faz referência a um participante ao qual é atribuído algo, ou sobre/em o qual se desenvolve algo, independentemente de sua vontade; caracterizase, portanto, como um participante menos voluntário e que detém menos controle sobre a situação, características estas compartilhadas com o actante paciente (Y) das construções biactanciais. Vejamos mais alguns exemplos:

$$
\begin{aligned}
& i \quad-\quad \text { i } \quad \text { - ku'uro } \\
& \text { p.3I.+ Atr.I+'estar morto' } \\
& \text { 'Ele está morto / morreu.' }
\end{aligned}
$$

$$
\begin{aligned}
& e \quad-\emptyset \quad \text { - 'ahek } \\
& \text { p.2I.+ Atr.I +'estar com bronquite' } \\
& \text { 'Você está com bronquite.' }
\end{aligned}
$$




$$
\begin{aligned}
& \text { a - i - 'ahek } \\
& \text { p.1Incl.I.+ Atr.I +'estar com bronquite' } \\
& \text { "Nós estamos com bronquite." }
\end{aligned}
$$

Já nos verbos médios uniactanciais, o actante único $(\mathrm{Z})$ indiciado no verbo apresenta a mesma forma que o agente $(\mathrm{X})$ das frases de ação biactanciais, o que se configura como um alinhamento acusativo $(Z=X)$, conforme mostram os exemplos abaixo:

$$
\begin{aligned}
& \text { a - ti - suk wewato } \\
& \text { p.1A.+ At.I + 'furar' 'anta/boi' } \\
& \text { 'Eu furei (a) anta/boi.' }
\end{aligned}
$$

$$
\begin{aligned}
& \text { a - re - potpa:p } \\
& \text { p.1A.+ Méd.I +'trabalhar' } \\
& \text { 'Eu trabalho.' }
\end{aligned}
$$

No exemplo (25) acima, tem-se um verbo ativo biactancial indiciado pelo prefixo pessoal $\{\mathrm{a}-\}$ "primeira pessoa", que faz referência ao agente (X) do processo denotado pelo verbo. Já no exemplo (26), tem-se um verbo médio uniactancial e o participante indiciado nesse verbo faz referência ao actante único $(Z)$. Pode-se dizer, portanto, que o alinhamento dos verbos médios uniactanciais é um alinhamento acusativo $(\mathrm{Z}=\mathrm{X})$, uma vez que o actante único $(Z)$ dessas construções apresenta a mesma forma que o actante agente $(\mathrm{X})$ das construções biactanciais.

Do ponto de vista semântico-referencial, o actante indiciado no verbo (Z) faz referência a um participante que é a origem de um processo, mas também sobre/em o qual o processo denotado pelo verbo se desenvolve; caracteriza-se como um participante mais voluntário e que detém mais o controle sobre a situação, conforme mostram os exemplos abaixo:

$$
\begin{aligned}
& e \quad-\text { re - ket } \\
& \text { p.2 A.+ Méd.I +'dormir' } \\
& \text { "Você dorme." }
\end{aligned}
$$




$$
\begin{aligned}
& \text { wa - to - popy } \\
& \text { p.1Incl.A. +Méd.I +'voar' } \\
& \text { 'Nós voamos > fugimos.' }
\end{aligned}
$$

Os exemplos (27) e (28) apresentam processos em que o participante indiciado no verbo $(Z)$ detém mais controle sobre a situação, embora em diferentes graus.

\section{Considerações finais}

A discussão dos dados do Mawé apresentados aqui mostra a existência de lexemas verbais uniactanciais que se distribuem em dois grupos, de acordo com o tipo de alinhamento: um ergativo $(Z=Y)$, o dos verbos de estado, e outro acusativo $(Z=X)$, o dos verbos médios, sendo essas duas construções de mesma importância na língua. Essa língua se caracteriza, portanto, como uma língua dual (ou ativa), dentro do quadro teórico aqui adotado (cf. Lazard, 1994), é também aquele em que melhor se encaixam os dados do Mawé.

\section{Referências}

Creissels, D. 2006. Syntaxe générale: une introduction typologique, volumes 1-2 (1: «Catégories et constructions», 2: «La phrase»), Paris: Lavoisier.

Franceschini, D. 1999. La langue Sateré-Mawé - description et analyse morphosyntaxique. Tese de doutorado, Universidade de Paris VII (Denis Diderot), Paris.

Franceschini, D. 2002. A voz inversa em Sateré-Mawé. Em: Ana Suelly A.C. Cabral e Aryon D. Rodrigues (orgs.), Atas do I Encontro Internacional do Grupo de Trabalho sobre Línguas Indigenas da ANPOLL: Línguas Indígenas Brasileiras: Fonologia, Gramática e História, volume I, 222233. Belém: Editora da Universidade Federal do Pará.

Franceschini, D. 2010. A orientação e o aspecto verbal em Sateré-Mawé (Tupi). Em: Revista Estudos da Linguagem - RELIN 18. 1. Belo Horizonte: Editora da Universidade Federal de Minas Gerais.

Lazard, G. 1994. L'actance. Paris: PUF.

Teixeira, Pery (org.).2005. Sateré-Mawé - retrato de um povo indígena. Manaus.

Rodrigues, Aryon Dall'Igna. 1984/1985. Relações Internas na Família Linguística Tupí-Guaraní. Revista de Antropologia, v. 27/28:33-53. São Paulo: USP. 